\title{
Vitamin D supplementation does not improve human skeletal muscle contractile properties in insufficient young males
}

\author{
Daniel J. Owens · Daniel Webber · Samuel G. Impey • \\ Jonathan Tang · Timothy F. Donovan - William D. Fraser • \\ James P. Morton • Graeme L. Close
}

Received: 30 July 2013 / Accepted: 28 February 2014

(C) Springer-Verlag Berlin Heidelberg 2014

\begin{abstract}
Purpose Vitamin D may be a regulator of skeletal muscle function, although human trials investigating this hypothesis are limited to predominantly elderly populations. We aimed to assess the effect of oral vitamin $D_{3}$ in healthy young males upon skeletal muscle function.

Methods Participants $(n=29)$ received an oral dose of $10,000 \mathrm{IU}_{\text {day }}{ }^{-1}$ vitamin $\mathrm{D}_{3}$ (VITD) or a visually identical placebo (PLB) for 3 months. Serum 25[OH]D and intact parathyroid hormone (iPTH) were measured at baseline and at week 4, 8 and 12. Muscle function was assessed in $n=22$ participants by isokinetic dynamometry and percutaneous isometric electromyostimulation at baseline and at week 6 and 12.

Results Baseline mean total serum 25[OH]D was $40 \pm 17$ and $41 \pm 20 \mathrm{nmol} \mathrm{L^{-1 }}$ for PLB and VITD, respectively. VITD showed a significant improvement in total $25[\mathrm{OH}] \mathrm{D}$ at week $4\left(150 \pm 31 \mathrm{nmol} \mathrm{L}^{-1}\right)$ that remained elevated throughout the trial $(P<0.005)$. Contrastingly, PLB showed a significant decrease in $25[\mathrm{OH}] \mathrm{D}$ at week
\end{abstract}

Communicated by Alain Martin

D. J. Owens · D. Webber · S. G. Impey $\cdot$ J. P. Morton ·

G. L. Close $(\bowtie)$

Research Institute for Sport and Exercise Science, Liverpool John Moores University, Tom Reilly Building, Byrom Street, Liverpool L3 3AF, UK

e-mail: g.l.close@ljmu.ac.uk

J. Tang $\cdot$ W. D. Fraser

Faculty of Medicine and Health Sciences, Norwich Medical

School, University of East Anglia, Norwich, UK

T. F. Donovan

Sport and Exercise Sciences, Glyndwr University,

Plas Coch Campus, Wrexham, UK $12\left(25 \pm 15 \mathrm{nmol} \mathrm{L}^{-1}\right)$ compared with baseline. Despite marked increases in total serum 25[OH]D in VITD and a decrease in PLB, there were no significant changes in any of the muscle function outcome measures at week 6 or 12 for either group $(P>0.05)$.

Conclusions Elevating total serum 25[OH]D to concentrations $>120 \mathrm{nmol} \mathrm{L^{-1 }}$ has no effect on skeletal muscle function. We postulate that skeletal muscle function is only perturbed in conditions of severe deficiency $\left(<12.5 \mathrm{nmol} \mathrm{L}^{-1}\right)$.

Keywords Cholecalciferol $\cdot 25$-Hydroxyvitamin D · Supplementation · Isokinetic dynamometry · Electromyostimulation · Fatigue

$\begin{array}{ll}\begin{array}{l}\text { Abbreviations } \\ 25[\mathrm{OH}] \mathrm{D}\end{array} & \text { 25-Hydroxyvitamin D } \\ 1,25[\mathrm{OH}] \mathrm{D} & \text { 1,25-Dihydroxyvitamin } \\ \mathrm{Ca}^{2+} & \text { Calcium, Ionized } \\ \text { ECLIA } & \begin{array}{l}\text { Enzyme-linked chemiluminescent } \\ \text { immunosorbent assay }\end{array} \\ \text { EMS } & \text { Electromyostimulation } \\ \text { FDA } & \text { Food and Drug Agency } \\ \text { iPTH } & \text { Intact parathyroid hormone } \\ \text { IU } & \text { International units } \\ \text { IKD } & \text { Isokinetic dynamometry } \\ \text { LC-MS/MS } & \text { Liquid chromatography tandem mass } \\ & \text { spectrometry } \\ \text { LLOQ } & \text { Lower limit of quantification } \\ \mathrm{N} & \text { Newtons } \\ \text { Nm } & \text { Newton metres } \\ \text { nmol L } & \text { Nanomoles per litre } \\ \text { PAR-Q } & \text { Physical activity readiness Questionnaire } \\ \text { Pmol L } & \text { Picomoles per litre } \\ \text { rad s } & \text { Radians per second }\end{array}$


RDI Recommended daily intake

US IoM United States Institute of Medicine UVB Ultraviolet B

\section{Introduction}

Vitamin D is classically regarded as a vital endocrine regulator of bone health via its role in calcium and phosphate homeostasis (Anderson et al. 2012). However, a myriad of non-skeletal effects of the steroid hormone are now known and are predominantly attributable to the identification of the vitamin $\mathrm{D}$ receptor in virtually all tissues (Rosen et al. 2012) including skeletal muscle (Srikuea et al. 2012). Genome-wide analyses suggest that any improvement in vitamin D status significantly affects the expression of a large number of genes that have many biological functions (Hossein-nezhad et al. 2013). Specifically regarding skeletal muscle, it has long been understood that patients with osteomalacia resultant from inadequate dietary vitamin D intake often display an accompanying skeletal muscle myopathy presenting as a proximal muscle weakness that is responsive to vitamin D supplementation (Ziambaras and Dagogo-Jack 1997; Irani 1976; Smith and Stern 1967; Al-Said et al. 2009). Emerging data now suggest at a cellular level that skeletal muscle is indeed a tissue that responds functionally to vitamin $\mathrm{D}$. Recent data have demonstrated in vivo improvements in mitochondrial oxidative function when severe vitamin D deficiency is corrected in humans (Sinha et al. 2013). Moreover, studies in chick embryo myoblast cultures have provided robust evidence that vitamin $\mathrm{D}$ is a regulator of intracellular $\mathrm{Ca}^{2+}$ concentration (Capiati et al. 2000; Morelli et al. 1993), which has also been observed in vivo in chicks (Vazquez et al. 1995 ) and in vitro in fully differentiated soleus muscle (de Boland et al. 1988). Vitamin D may therefore be implicated in skeletal muscle contractility, which early reports from vitamin D depleted rats have alluded to (Rodman and Baker 1978). Aside from these observations, reports suggest a role for the bioactive vitamin $\mathrm{D}$ compound 1,25-dihydroxyvitamin D (or 1,25[OH]D) in signalling pathways which involved myoblast proliferation and differentiation indicating a key role for vitamin D in muscle cell development and survival (Garcia et al. 2013; Srikuea et al. 2012; Stratos et al. 2013). Despite such evidence, vitamin D deficiency is still widespread around the globe (van Schoor and Lips 2011). We have previously shown that this observation is consistent in sub-populations of professional athletes and healthy, young athletic cohorts (Morton et al. 2012; Close et al. 2013a, b).

A number of trials have sought to assess the effect of vitamin D status on muscle function at a macroscopic scale. Insights from these investigations have established a link between vitamin D status and falls and various other physical performance measures such as handgrip, lower limb strength, balance and gait speed (Bischoff-Ferrari et al. 2004; Gerdhem et al. 2005; Houston et al. 2007; Marantes et al. 2011). However, such trials are limited to predominantly geriatric or clinical populations, and it is difficult to generalise such findings to young healthy populations, due to age-related skeletal muscle disease (i.e. sarcopenia). The few trials that have been conducted in young otherwise healthy cohorts have resulted in equivocal findings, with some investigations reporting beneficial effects of vitamin D supplementation in muscle (Sinha et al. 2013; Close et al. 2013b) and others observing no perceptible changes following supplementation (Close et al. 2013a). Hampering such findings further is large heterogeneity in outcome measures implemented to assess muscle function, low participant numbers, heterogeneity in supplementation protocols and varying baseline vitamin $\mathrm{D}$ status of the sample population making the cross comparison between findings difficult.

Adding further complexity to this issue is that the daily requirement for vitamin $\mathrm{D}$ needed to elevate total serum vitamin $\mathrm{D}$ concentrations to a level necessary for optimal physiological function is a point of debate. With regard to dose, the United States Institute of Medicine (US IoM) has set the RDI for vitamin D at $600 \mathrm{IU}_{\text {day }}{ }^{-1}$ for young adults and tolerable upper intake at 4,000 $\mathrm{IU}_{\text {day }}{ }^{-1}$ (IoM 2011), although the US IoM set the 'no observed adverse effect limit' (NOAEL) at 10,000 IU day ${ }^{-1}$ (IoM 2011). In relation to total serum 25-hydroxyvitamin D (or 25[OH] D) concentration, the US IoM suggest $>50 \mathrm{nmol} \mathrm{L}^{-1}$ as adequate whilst suggesting that concentrations exceeding $125 \mathrm{nmol} \mathrm{L}^{-1}$ may be detrimental to health. Others have suggested that these guidelines are too conservative and claim values exhibited in those living outdoors in sun-rich climates $\left(\sim 100 \mathrm{nmol} \mathrm{L}{ }^{-1}\right)$ to be adequate, since they reflect the values present when the human genome evolved in such rich environments around equatorial Africa (Vieth 2011; Heaney 2011). An 'optimal' 25[OH]D concentration for muscle function is currently still elusive and no study till date has tested the hypothesis that elevating serum $25[\mathrm{OH}]$ D concentrations to $>120 \mathrm{nmol} \mathrm{L}^{-1}$ is optimal for muscle function in healthy recreationally active individuals, as previously suggested (Heaney 2011). Our group has previously implemented doses of 20,000 and 40,000 IU week ${ }^{-1}$ oral vitamin $\mathrm{D}_{3}$, but failed to elevate serum concentrations $>100 \mathrm{nmol} \mathrm{L}^{-1}$ (Close et al. 2013a). Thus higher doses may be necessary to achieve a total serum $25[\mathrm{OH}] \mathrm{D}$ concentration $>100 \mathrm{nmol} \mathrm{L}^{-1}$.

Given the available evidence and a clear lack of data in the area, we sought to investigate the impact of vitamin D status on lower limb muscle function using valid macroscopic techniques including percutaneous isometric 
myostimulation (IMS) and isokinetic dynamometry (IKD) in healthy, recreationally active young men. We hypothesized that supplementing with high dose oral vitamin $\mathrm{D}_{3}$ (cholecalciferol) to elevate total serum $25[\mathrm{OH}] \mathrm{D}$ concentrations > $100 \mathrm{nmol} \mathrm{L}^{-1}$ (suggested optimal Zittermann 2003; Heaney 2011; Vieth 2011) would have a beneficial effect on our chosen outcome measures of muscle function.

\section{Methodology}

\section{Participants}

Twenty-nine male participants (age $=22.7 \pm 3$ years; height $=179.3 \pm 5.9 \mathrm{~cm}$; weight $=76.1 \pm 16.2 \mathrm{~kg}$ ) volunteered to partake in the current trial. Participants received detailed information regarding the study procedures and were required to complete a PAR-Q, a medical history questionnaire and provide written informed consent before inclusion in the trial. Strict exclusion criteria were implemented for participant safety and validity of the investigation. Participants were excluded if they had underlying health problems as identified by completion of the medical history questionnaire, were sunbed users or taking vitamin D supplementation, standard oral multivitamins or, currently unfit to perform physical exercise, currently taking prescribed medication and those who expected a drastic change in their physical activity/training routine during the trial. After meeting these initial inclusion criteria, participants provided a venous blood sample that was analysed for total 25-hydroxyvitamin D (25[OH]D) concentration. Those presenting with total serum 25[OH]D concentrations $\geq 100 \mathrm{nmol} \mathrm{L}^{-1}$ were excluded from the trial. Ethical approval was granted by the local ethics committee of Liverpool John Moores University, and all data were collected in accordance with the Declaration of Helsinki.

Participants were block randomized based on their baseline 25[OH]D concentration and electrically evoked $20 \mathrm{~Hz}$ isometric knee extensor force into two experimental groups. Of the 29 initial participants, 22 completed all test procedures whilst the remaining 6 only took part in supplementation and blood sampling and one dropped out. This was due to an inability on the participants' behalf to commit sufficient time for each testing point. Fourteen participants were assigned to an oral vitamin D treatment group (VITD) and 15 participants were initially assigned to a visually identical placebo control group (PLB) (see Table 1).

\section{Vitamin D supplementation}

Participants allocated to VITD received $10,000 \mathrm{IU}$ day $^{-1}$ of vitamin $\mathrm{D}_{3}$ (Bio-Tech Pharmacal. Arkansas, USA) taken
Table 1 Block randomization data including mean total serum $25[\mathrm{OH}] \mathrm{D}$ concentration presented as nmol L ${ }^{-1}$ and mean isometric force from a single stimulation at a frequency of $20 \mathrm{~Hz}$ and stimulation intensity of $130 \mathrm{~mA}$

\begin{tabular}{llc}
\hline & PLB & VITD \\
\hline Mean total 25[OH]D $\left(\mathrm{nmol} \mathrm{L}^{-1}\right)$ & 40 & 41 \\
$\pm \mathrm{SD}$ & 17 & 21 \\
$t$ test & $t=0.867, P=0.876$ \\
Mean isometric force $(\mathrm{N})$ & 267 & 307 \\
$\pm \mathrm{SD}$ & 69 & 67 \\
$t$ test & $t=-1.086, P=0.303$ \\
\hline
\end{tabular}

as two 5,000 IU gelatin capsules. Those allocated to PLB received two visually identical placebo capsules each containing $90 \mathrm{mg}$ cellulose (Bio-Tech Pharmacal. Arkansas, USA). The supplementation period lasted 12 weeks between the months of January and April to achieve a plateau in serum $25[\mathrm{OH}] \mathrm{D}$ response, as previously shown in a dose response trial with $10,000 \mathrm{IU}_{\text {day }}{ }^{-1}$ vitamin $\mathrm{D}_{3}$ cholecalciferol (Heaney et al. 2003). Both researcher and participant were blinded until completion of the study procedures.

\section{Blood sampling}

For the analysis of vitamin D metabolites and iPTH, participants provided a fasted venous blood sample collected from the antecubital vein into two $\mathrm{K}_{2}$ EDTA plasma $(10 \mathrm{ml})$ vacutainers and two serum separator [(SST) $8.5 \mathrm{ml}$ ] vacutainers (Beckton Dickinson. Oxford, UK) prior to supplementation and then at 4,8 and 12 weeks post-supplementation. SST samples were allowed to clot for $1 \mathrm{~h}$ at room temperature whilst $\mathrm{K}_{2}$ EDTA samples were immediately stored on ice, following which all samples were centrifuged for $15 \mathrm{~min}$ at $1,500 \mathrm{rcf}$ at $4{ }^{\circ} \mathrm{C}$. Serum and plasma were extracted and stored at $-80^{\circ} \mathrm{C}$ until required for analysis.

Analysis of vitamin D metabolites and intact parathyroid hormone (iPTH) concentration

For the analysis of vitamin $\mathrm{D}$ concentration $25(\mathrm{OH}) \mathrm{D}_{2}$, $25(\mathrm{OH}) \mathrm{D}_{3}$ were extracted from serum samples, following zinc sulphate protein precipitation, using Isolute $\mathrm{C} 18$ solid phase extraction cartridges. Potential interfering compounds were removed by initial elution with $50 \%$ methanol followed by elution of the vitamins using $10 \%$ tetrahydrofuran in acetonitrile. Dried extracts were reconstituted prior to injection into a high performance liquid chromatography tandem mass spectrometer (LC-MS/ MS) in the multiple reaction mode. The multiple reaction mode transitions $(\mathrm{m} / \mathrm{z})$ used were $413.2>395.3$, $401.1>383.3$ and, $407.5>107.2$ for $25(\mathrm{OH}) \mathrm{D}_{2}, 25(\mathrm{OH})$ $\mathrm{D}_{3}$, and hexa-deuterated $[\mathrm{OH}] \mathrm{D}_{3}$, respectively. The assay 
Table 2 (A) Imprecision of the LC-MS/MS assay and (B) Recovery efficiency of the assay

\begin{tabular}{|c|c|c|c|c|c|c|c|c|c|}
\hline \multicolumn{10}{|l|}{ A } \\
\hline \multirow{2}{*}{\multicolumn{2}{|c|}{$\mathrm{nmol} \mathrm{L}^{-1}$}} & \multicolumn{3}{|c|}{ Chromsystem 1} & \multicolumn{3}{|c|}{ Chromsystem 2} & \multicolumn{2}{|l|}{ Calf serum } \\
\hline & & \multirow[t]{2}{*}{ Vitamin D3 } & \multicolumn{2}{|c|}{ Vitamin D2 } & \multicolumn{2}{|c|}{ Vitamin D3 } & Vitamin D2 & Vitamin D3 & Vitamin D2 \\
\hline \multicolumn{9}{|c|}{ Intra-assay precision } & \\
\hline \multicolumn{2}{|l|}{ Mean } & 42.9 & 43.4 & & 80.2 & & 81.1 & 6.9 & 7.8 \\
\hline \multicolumn{2}{|l|}{ SD } & 4.1 & 3.4 & & 7.8 & & 8.6 & 0.7 & 0.8 \\
\hline \multicolumn{2}{|l|}{$\% \mathrm{CV}$} & 9.5 & 7.8 & & 9.7 & & 10.6 & 10.1 & 10.2 \\
\hline \multicolumn{10}{|c|}{ Inter-assay precision } \\
\hline \multicolumn{2}{|l|}{ Mean } & 40.4 & 32.4 & & 76.8 & & 95.3 & 7.7 & 7.8 \\
\hline \multicolumn{2}{|l|}{ SD } & 2.4 & 3.3 & & 7.2 & & 8.3 & 0.7 & 0.9 \\
\hline \multicolumn{2}{|l|}{$\% \mathrm{CV}$} & 6 & 10 & & 9.3 & & 8.7 & 9.1 & 10.8 \\
\hline \multicolumn{10}{|l|}{ B } \\
\hline & \multicolumn{3}{|c|}{ Endogenous $25[\mathrm{OH}] \mathrm{D}_{3}\left(\mathrm{nmol} \mathrm{L}^{-1}\right)$} & Spike & $\left.\mathrm{ol} \mathrm{L} \mathrm{L}^{-1}\right)$ & \multicolumn{4}{|c|}{ Measured value $\left(\mathrm{nmol} \mathrm{L}^{-1}\right) \%$ Recovery } \\
\hline Sample 1 & \multicolumn{3}{|l|}{5.5} & 50 & & \multicolumn{2}{|l|}{53.7} & \multicolumn{2}{|l|}{96.4} \\
\hline Sample 2 & \multicolumn{3}{|l|}{10.2} & 100 & & \multicolumn{2}{|c|}{103.4} & \multicolumn{2}{|l|}{93.8} \\
\hline \multirow[t]{2}{*}{ Blank } & \multicolumn{3}{|l|}{0} & 500 & & \multicolumn{2}{|l|}{491} & \multicolumn{2}{|l|}{98.2} \\
\hline & \multicolumn{3}{|c|}{ Endogenous $25[\mathrm{OH}] \mathrm{D}_{2}\left(\mathrm{nmol} \mathrm{L}^{-1}\right)$} & Spike & $\left.\mathrm{ol} \mathrm{L}^{-1}\right)$ & \multicolumn{3}{|c|}{ Measured value (nmol L ${ }^{-1}$ ) \%Recovery } & \\
\hline Sample 1 & 37.0 & & & 50 & & 84 & & 96.5 & \\
\hline Sample 2 & 80.2 & & & 100 & & 171 & & 95 & \\
\hline Blank & 0 & & & 500 & & 479 & & 95.8 & \\
\hline
\end{tabular}

Intra precision was assessed by running quality control materials (Chromsystems) and commercially bought material (calf serum) ten times $(n=10)$ within a single run, and separately over 15 runs $(n=15)$ for inter-assay assessment. Variation is expressed as standard deviation (SD) and percentage of coefficient of variation $(\% \mathrm{CV})$

was validated against published acceptance criteria (FDA 2001). Assay sensitivity was determined by the lower limit of quantification (LLOQ): $25[\mathrm{OH}] \mathrm{D} 3=2.5 \mathrm{nmol} \mathrm{L}-1$ and $25[\mathrm{OH}] \mathrm{D} 2=2.5 \mathrm{nmol} \mathrm{L}^{-1}$. Coefficients of variation $(\mathrm{CVs})$ for the assay were $10 \%$ across a working range of $2.5-625 \mathrm{nmol} \mathrm{L}^{-1}$ for both $25[\mathrm{OH}) \mathrm{D}_{2}$ and $25(\mathrm{OH}) \mathrm{D}_{3}$. Data regarding assay precision, detection and recovery are provided in Table 2A, B. Table 2A demonstrates imprecision of the assay and $2 \mathrm{~B}$ shows recovery efficiency. Intra-assay precision was assessed by running quality control materials (Chromsystems Instruments and chemicals. Gräfelfing, Germany) and commercially bought material (calf serum) ten times $(n=10)$ within a single run, and separately over 15 runs $(n=15)$ for inter-assay assessment. Values used to determine assay variation are expressed as SD and \%CV. Acceptance criteria define that $\% \mathrm{CV}$ should not exceed $10 \%$ in both intra- and inter-assay (Table 2A). Extraction recovery was assessed by determining the amount of vitamin $\mathrm{D}_{3} / \mathrm{D}_{2}$ recovered from the amount spiked prior to extraction. The percentage recovery was calculated by the measured value against the sum of endogenous value and spiking concentration. Spiked recovery is determined by adding known quantity of 25[OH]D3/D2 to serum samples with different levels of endogenous 25[OH]D (Table 2B). The data demonstrate good assay recovery, indicating that the procedure was able to efficiently extract vitamin D from matrix and the method was able to determine the amount recovered accurately. MassCheck calibration materials and controls are traceable against NIST 972 reference material. Furthermore, the LC-MS/MS method of analysis has previously been validated against other commercially available assays and is regarded as the most valid and reliable technique for the assessment of vitamin D metabolites (Snellman et al. 2010).

Classification of vitamin D status was based upon the US IoM (2011) guidelines (see Table 3).

For the analysis of iPTH, an Elecsys electrochemiluminescent immunoassay (ECLIA) by Cobas (Roche Diagnostics. Indianapolis, USA) was implemented. Fifty $\mu \mathrm{L}$ of plasma, a biotinylated monoclonal PTH-specific antibody and monoclonal PTH-specific antibody labelled with a ruthenium complex were formed into a sandwich complex. After addition of streptavidin-coated microparticles, the complex became bound to the solid phase via interaction of biotin and streptavidin. The reaction mixture was aspirated into the measuring cell where the microparticles 
Table 3 The US IoM (2011) guidelines for vitamin D status and suggested optimal concentrations (Zittermann 2003)

\begin{tabular}{ll}
\hline Serum $25[\mathrm{OH}] \mathrm{D}\left(\mathrm{nmol} \mathrm{L}^{-1}\right)$ & Status \\
\hline$<12$ & Severely deficient \\
12 to $<30$ & Deficient \\
30 to 50 & Inadequate \\
$>50$ & Adequate \\
$>100$ to 250 & Suggested optimal (Zittermann 2003) \\
$>120$ to 225 & Suggested optimal (Heaney 2011) \\
\hline
\end{tabular}

were magnetically captured onto the surface of the electrode. Unbound substances were then removed with ProCell. Application of a voltage to the electrode then induces chemiluminescent emission which is measured by a photomultiplier. Results were determined via a calibration curve which is instrument-specifically generated by twopoint calibration and a five-point master curve provided via the reagent barcode. The measuring range of the assay was $0.127-530 \mathrm{pmol} \mathrm{L}^{-1}$ (defined by the lower detection limit and the maximum of the master curve). The Elecsys ECLIA has previously been validated by multicentre evaluation as a valid and reliable measure of iPTH concentration (Hermsen et al. 2002).

\section{Assessment of lower limb muscle function}

A number of outcome measures were employed to validly assess muscle function of the lower limb. Participants completed both an IKD protocol and EMS protocol. All tests were completed at baseline, week 6 and week 12 of supplementation apart from IKD, which was only completed at baseline and week 12 .

\section{Isokinetic dynamometry}

Isokinetic torque was assessed on a Biodex isokinetic dynamometer (Biodex Medical Systems Inc. Shirley, NY, USA), previously validated for its use in reliable assessment of muscle function variables related to force production (Drouin et al. 2004). Participants were seated as per the manufacturer's guidelines with a $90^{\circ}$ flexion of the hip and non-extendable straps crossing the chest and abdomen and across the quadriceps to maximise isolation of the target muscle groups. The test protocol consisted of four consecutive maximal extension and flexion movements (Baltzopoulos and Brodie 1989) of the right quadriceps and hamstrings at two different fixed angular velocities, $1.05 \mathrm{rad} \mathrm{s}^{-1}\left(60 \mathrm{deg} \mathrm{s}^{-1}\right)$ and $3.14 \mathrm{rad} \mathrm{s}^{-1}\left(180 \mathrm{deg} \mathrm{s}^{-1}\right)$ from which peak torque $(\mathrm{Nm})$ was generated, separated by a 5-min rest to allow full recovery of the high energy phosphate pool (Soderlund and Hultman 1991). Testing at
Table 4 Co-efficient of variation for each isokinetic dynamometry variable

\begin{tabular}{lllll}
\hline $\begin{array}{l}\text { Measurement } \\
\text { variable }\end{array}$ & $\begin{array}{l}\text { Flexion } \\
1.05 \mathrm{rad} \mathrm{s}^{-1}\end{array}$ & $\begin{array}{l}\text { Extension } \\
1.05 \mathrm{rad} \mathrm{s}^{-1}\end{array}$ & $\begin{array}{l}\text { Flexion } \\
3.14 \mathrm{rad} \mathrm{s}^{-1}\end{array}$ & $\begin{array}{l}\text { Extension } \\
3.14 \mathrm{rad} \mathrm{s}^{-1}\end{array}$ \\
\hline $\mathrm{CV} \%$ & 3.9 & 3.7 & 4.9 & 4.1 \\
\hline
\end{tabular}

Data are presented as group means from familiarization trials. $1.05 \mathrm{rad} \mathrm{s}^{-1}=60 \mathrm{deg} \mathrm{s}^{-1} ; 3.14 \mathrm{rad} \mathrm{s}^{-1}=180 \mathrm{deg} \mathrm{s}^{-1}$

two angular velocities produces valuable information as to how peak torque is produced by during different activation patterns (Baltzopoulos and Brodie 1989) as it is understood that neurological activation patterns of motor units changes as the angular velocity increases e.g. from 60 to $180 \mathrm{deg} \mathrm{s}^{-1}$ (Lesmes et al. 1978) thus replicating different locomotive activities. All participants were familiarized with the protocol until the coefficient of variation for each participant was $<10 \%$ (Atkinson and Nevill 1998) (Table 4).

\section{Percutaneous isometric electromyostimulation}

Stimulation was applied through surface electrodes, delivered via a BIOPAC systems MP100 stimulator (BIOPAC systems inc, Santa Barbara, CA, USA) and knee extension forces were recorded with a tension compression load cell (Tedea-Huntleigh, Vishay Precision Group Inc. Malvern, PA, USA) connected to a non-extendable strap attached to the participants' lower leg approximately $2-3$ inches from the malleolus. Information collected from the force transducer was visualized and analysed using AcqKnowledge v.3.7.2 software (BIOPAC systems inc. Santa Barbara, CA, USA). Muscles were stimulated at an intensity of $130 \mathrm{~mA}$ for each test procedure as described previously (Gerrits et al. 2002). For the determination of muscle contractile properties, contraction was evoked by a $1-\mathrm{Hz}$ twitch. For the determination of fatigue resistance, contractions were evoked by $20 \mathrm{~Hz}, 200-\mathrm{ms}$ square wave pulses, previously defined to be representative of normal voluntary human motor neurone firing rates (Bigland-Ritchie et al. 1979), and thus physiologically valid when used to assess the fatigue resistance of human skeletal muscle.

For every session, the position of the participant in the isometric chair (Lido Active, Loredan, Davis, CA, USA) was standardized in accordance with guidelines previously published (Morton et al. 2005). Two $3 \times 5$ inch $(8 \times 13 \mathrm{~cm})$ oval self-adhesive stimulating electrodes (Chattanooga, DJO Global, CA, USA) were placed approximately 2 inches above the knee joint across the vastus medialis (VM) and proximal to the acetabulofemoral joint across the vastus lateralis (VL). Participants were required to fully extend and contract the quadriceps to make the muscle body more apparent prior to electrode placement 
to minimise antagonist coactivation, although this was not monitored with electromyography during stimulation.

To determine time to peak twitch and half relaxation time, a 1-Hz, 200-ms square wave pulse was administered. Time to peak twitch was determined as the time taken to reach peak isometric force from the onset of stimulation. Half relaxation time was determined as the time from peak stimulated force to reach half peak stimulated force. Testretest reliability data revealed that the $\mathrm{CV} \%$ for time to peak twitch and for $1 / 2$ relaxation time as determined by a $1-\mathrm{Hz}$ twitch at $130 \mathrm{~mA}$ was 4.5 and $5.7 \%$, respectively. Fatigue resistance was determined from 2 min repeated stimulation with $20 \mathrm{~Hz}, 200$-ms square wave pulses every $750 \mathrm{~ms}$ (total of 160 evoked contractions equating to $32 \mathrm{~s}$ of total stimulation). Fatigue index was calculated as absolute force loss from the first stimulated contraction to the final stimulated contraction.

\section{Statistical methods}

A power calculation was performed by a priori using Minitab software (v.16) to allow for any dropouts based on detecting a significant change in serum $25[\mathrm{OH}] \mathrm{D}$ and increased peak torque in response to vitamin $\mathrm{D}$ supplementation. Pilot work from our laboratories during the winter months suggested that the standard deviation for test-retest serum 25[OH]D concentrations (taken 6 weeks apart) in

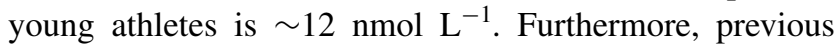
work from our laboratory demonstrated that standard deviation in isokinetic force at $1.04 \mathrm{rad} \mathrm{s}^{-1}\left(60 \mathrm{deg} \mathrm{s}^{-1}\right)$ is $~ 35$ $\mathrm{Nm}$. To enable the detection of a $50 \mathrm{nmol} \mathrm{L}{ }^{-1}$ increase in total serum $25[\mathrm{OH}] \mathrm{D}$ concentration between pre-supplementation and post-supplementation with $80 \%$ power, $n=3$ participants per group was required. To enable a $10 \%(21 \mathrm{Nm})$ increase in peak torque between pre-supplementation and post-supplementation with $80 \%$ power, $n=12$ per experimental group was required. Therefore, we initially recruited 30 participants to allow for dropouts and maintain statistical power.

For determination of test-retest reliability in familiarization trials, a paired sample $t$ test was used. For the analyses of total serum $25[\mathrm{OH}] \mathrm{D}$, PTH and all muscle function measurement variables, a two-way mixed design ANOVA was implemented. Where an interaction between independent variables was detected, simple main effects were explored with a one-way ANOVA. Significant main effects were explored using the Bonferroni post-hoc procedure and $\alpha$ was set at 0.05 . In addition, a linear regression was plotted using Pearson's correlation to assess whether baseline $25[\mathrm{OH}] \mathrm{D}$ concentration was a predictor of $\Delta 25[\mathrm{OH}] \mathrm{D}$ in response to supplementation. All analyses were performed using SPSS (Predictive Analytics Software v.20, IBM Corporation, NY, USA). Data are presented as mean $\pm \mathrm{SD}$.

\section{Results}

Total serum 25[OH]D and iPTH

There was a significant interaction between group and time for total serum 25[OH]D $(P<0.005)$. Serum 25[OH] $\mathrm{D}$ concentration showed a significant main effect for time $(P<0.005)$ and treatment group $(P<0.005)$. Participants in VITD demonstrated significantly elevated total serum $25[\mathrm{OH}] \mathrm{D}$ concentrations at week 4 compared with baseline that remained elevated throughout the trial. Contrastingly, participants in PLB displayed total serum 25[OH] D concentrations significantly lower at week 12 compared with baseline (see Fig. 1a). In addition, regression analysis revealed that pre-treatment vitamin $\mathrm{D}$ concentration was a strong predictor of $25[\mathrm{OH}] \mathrm{D}$ response to supplementation in VITD, where $83 \%$ of the variation in response to supplementation was attributable to baseline concentration (see Fig. 1b). VITD showed no significant change in iPTH concentration throughout the trial $(P=0.322)$, whereas PLB showed a significant increase in iPTH concentration at week $4(P<0.005)$, which remained elevated throughout the trial (see Fig. 1c) showing an inverse relationship with serum $25[\mathrm{OH}] \mathrm{D}$.

\section{Maximum voluntary contraction}

There were no differences between experimental groups in peak torque production at either of the fixed movement velocities or for flexion/extension $(P=0.610)$. Furthermore there was no effect of experimental treatment as no changes were observed in peak torque production for either of the movement velocities or for flexion/extension following supplementation with $10,000 \mathrm{IU}_{\text {day }}{ }^{-1}$ vitamin $\mathrm{D}_{3}$ $(P=0.345$, see Fig. 2).

Fatigue resistance

The effects of vitamin D supplementation on fatigue resistance of the VL and VM muscles can be seen in Fig. 3. Data are presented as absolute maximal force (Fig. 3a) and percentage of maximal force (Fig. 3b), although statistical analysis was performed on the fatigue ratio of absolute data only. No significant interaction was detected between treatment group and time i.e. baseline, week 6 and week 12 $(P=0.134)$. However, approaching significant main effect was also not observed for experimental group $(P=0.063)$.

Time to peak twitch and half relaxation time

No significant differences were detected between treatment groups for time taken to reach peak isometric twitch force $(P=0.968)$ or half relaxation time $(P=0.924)$. 

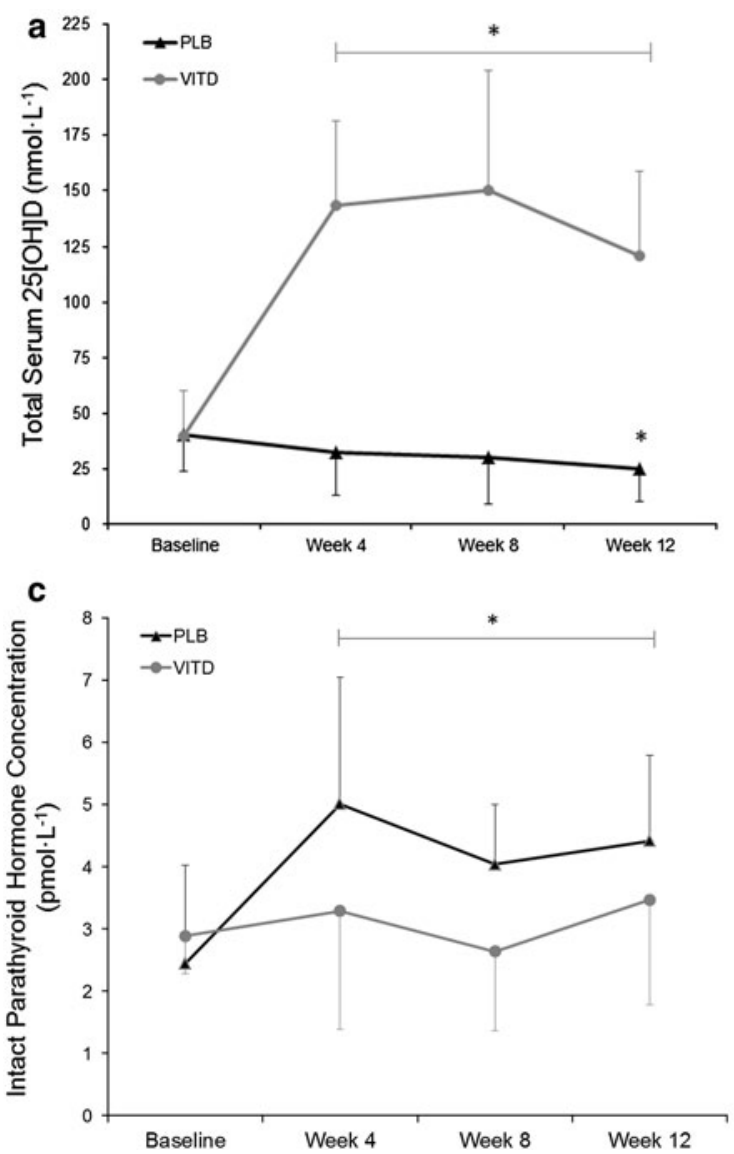

Fig. 1 a Response of total serum 25[OH]D to 12-week supplementation with $10,000 \mathrm{IU}$ day ${ }^{-1}$ vitamin $\mathrm{D}_{3}$ or placebo. $\mathbf{b}$ Linear regression describing the relationship between baseline vitamin $\mathrm{D}$ status and response to supplementation. Baseline total 25[OH]D concentration

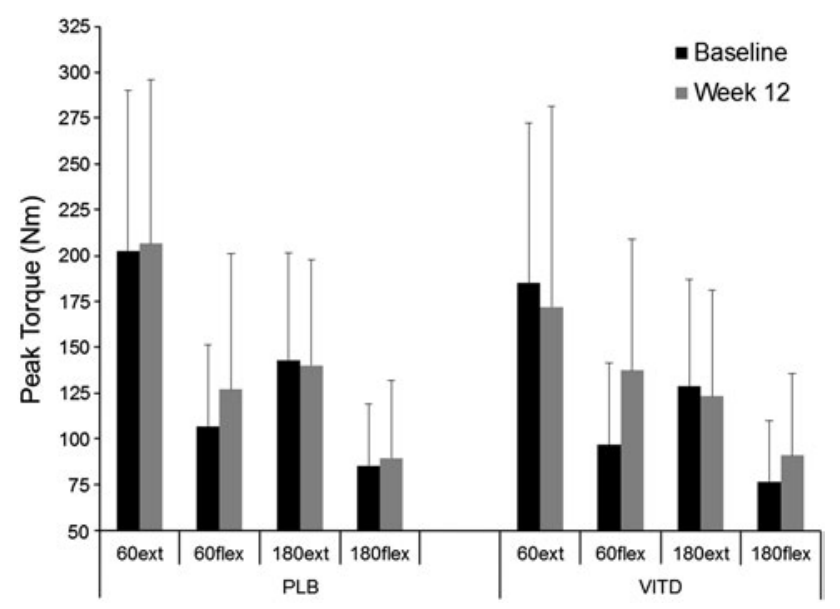

Fig. 2 Peak torque data from maximal extension (ext) and flexion (flex) of the right lower limb at two fixed velocities of $1.05 \mathrm{rad} \mathrm{s}^{-1}$ $\left(60^{\circ} \mathrm{s}^{-1}\right)$ and $3.14 \mathrm{rad} \mathrm{s}^{-1}\left(180^{\circ} \mathrm{s}^{-1}\right)$ prior to and following 12-week supplementation with $10,000 \mathrm{IU}$ day $^{-1}$ or placebo

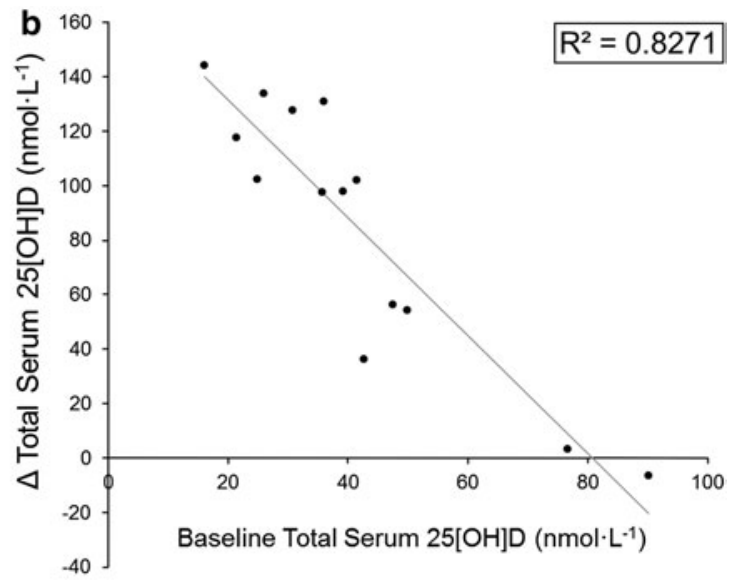

is the predictor variable whilst change in total $25[\mathrm{OH}] \mathrm{D}$ at 12 weeks is the response variable. $\mathbf{c}$ Response of intact parathyroid hormone to 12-week supplementation with $10,000 \mathrm{IU}_{\text {day }}{ }^{-1}$ vitamin $\mathrm{D}_{3}$ or placebo. (Asterisk) Denotes significance to baseline $(P<0.05)$

Furthermore, there was no significant effect of time for either time to peak twitch $(P=0.861)$ or half relaxation time $(P=0.293)$ indicating that a treatment effect was not observed (see Fig. 4).

\section{Discussion}

The aim of the current study was to investigate the impact of vitamin D status on muscle function in healthy, recreationally active young men. We hypothesized that supplementing with oral vitamin $\mathrm{D}_{3}$ (cholecalciferol) to elevate total serum 25[OH]D concentrations $>100 \mathrm{nmol} \mathrm{L}^{-1}$ (suggested optimal Zittermann 2003; Heaney 2011; Vieth 2011) would have a beneficial effect on muscle function. However, we demonstrate that in a population of predominantly vitamin $\mathrm{D}$ inadequate young men, supplementation with $10,000 \mathrm{IU} \mathrm{day}^{-1}$ effectively elevated total serum 25[OH]D 
Fig. 3 a Absolute isometric force and $\mathbf{b}$ percentage force loss during $120 \mathrm{~s}$ of repeated unilateral lower limb stimulation from an electrically evoked square wave pulse of $200 \mathrm{~ms}, 20 \mathrm{~Hz}$ and a stimulation intensity of $130 \mathrm{~mA}$, every $750 \mathrm{~ms}$. Data presented prior to supplementation (baseline) and then at week 6 and 12 of supplementation
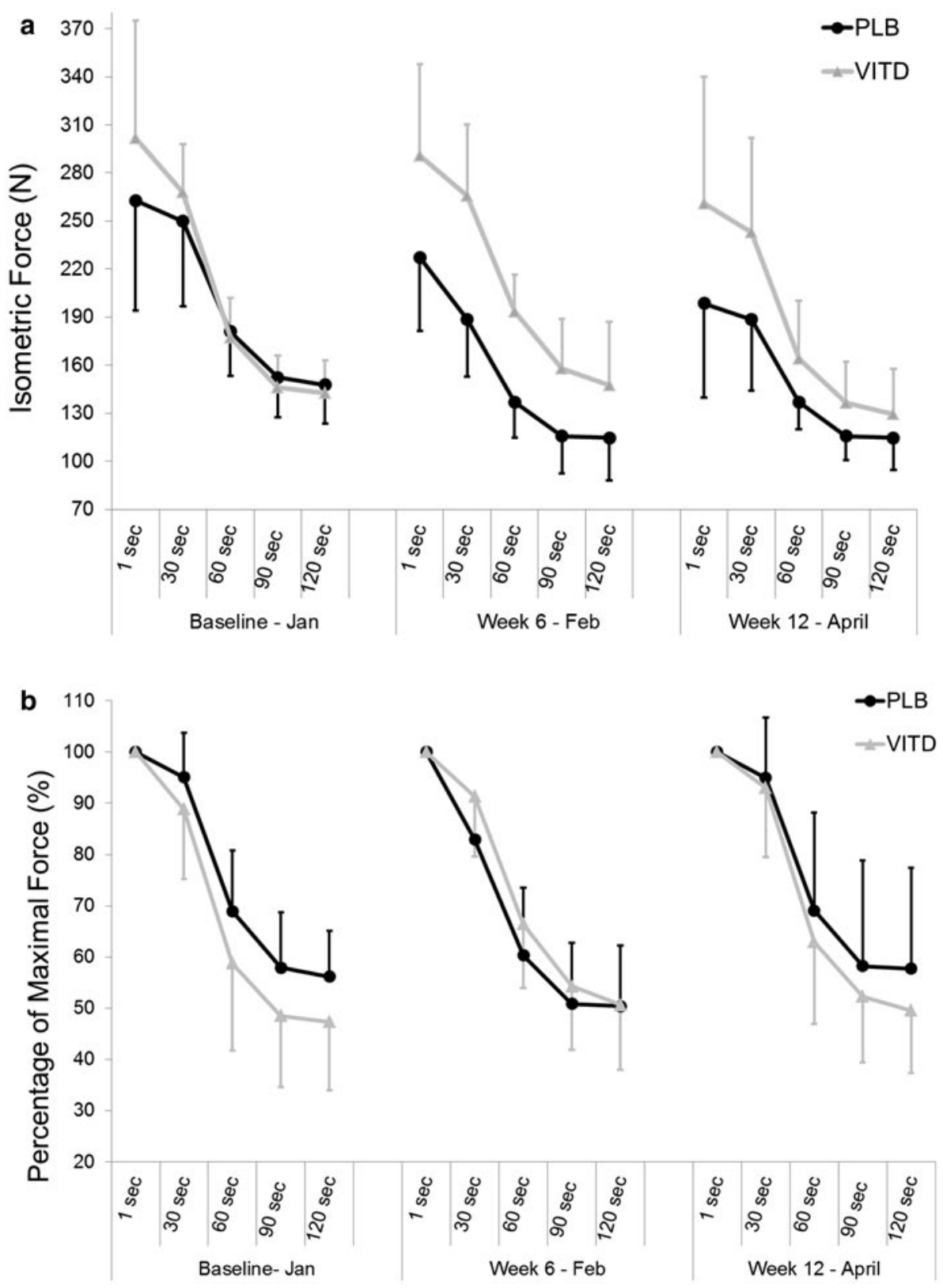

concentration to values $>100 \mathrm{nmol} \mathrm{L}^{-1}$; this had no effect (positive or negative) on muscle force, muscle fatigue or muscle contractile properties.

Our primary findings are in agreement with other randomized interventional trials assessing the impact of vitamin D supplementation on skeletal muscle function. Previous data from our group has demonstrated in a sample of 30 club level athletes with a mean 25[OH]D concentration of $51 \mathrm{nmol} \mathrm{L}^{-1}\left(\mathrm{SD} \pm 24 \mathrm{nmol} \mathrm{L}^{-1}\right)$ that neither 20,000 or $40,000 \mathrm{IU}$ week ${ }^{-1}$ of vitamin $\mathrm{D}_{3}$ for 12 weeks were effective in improving 1-RM bench press, leg press or vertical jump height, although both doses achieved a significant elevation of total serum 25[OH]D $(20,000$ and $40,000 \mathrm{IU}_{\text {day }}{ }^{-1}$ vitamin $\mathrm{D}_{3}=85 \pm 10 \mathrm{nmol} \mathrm{L}^{-1}$ and
$91 \pm 24 \mathrm{nmol} \mathrm{L}{ }^{-1}$, respectively) after 12 weeks (Close et al. 2013a). Similarly, other studies predominantly undertaken in elderly cohorts have failed to detect improvements in strength parameters following supplementation (Kukuljan et al. 2011; Kenny et al. 2003). As highlighted in a systematic review and meta-analysis, trials in which the sample population display serum concentrations $>25 \mathrm{nmol} \mathrm{L}^{-1}$ have failed to show improvements in muscle strength parameters following supplementation (Stockton et al. 2011).

We also report that elevating serum 25[OH] D > $100 \mathrm{nmol} \mathrm{L}{ }^{-1}$ does not negate the force producing capacity, fatigue resistance or contractile properties of skeletal muscle in humans, an idea that has previously 

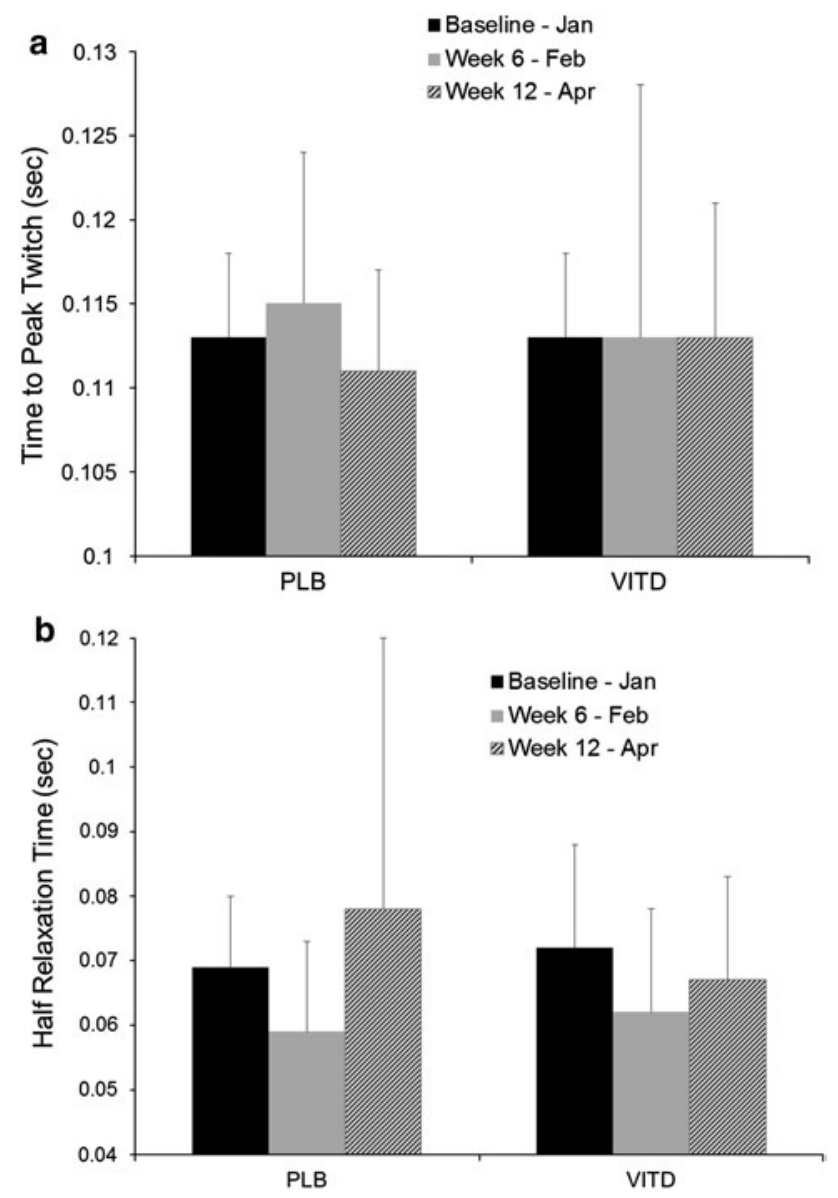

Fig. 4 Muscle contractile properties from an electrically evoked $1-\mathrm{Hz}$ twitch and a stimulation intensity of $130 \mathrm{~mA}$. Data are displayed from baseline, 6 and 12 weeks of supplementation with $10,000 \mathrm{IU}_{\text {day }}{ }^{-1}$ vitamin $\mathrm{D}_{3}$ or placebo

been suggested; One randomized controlled trial has previously reported that annual high dose vitamin $D_{3}$ (500,000 IU) effectively elevated serum concentrations of 25[OH]D to approximately $120 \mathrm{nmol} \mathrm{L}^{-1}$ in community dwelling older women (Sanders et al. 2010). However, this resulted in an increased risk of falls and fractures compared with a placebo control group. This observation could be attributable to the dosing strategy implemented, as smaller but more frequent doses in other RCT's do not show comparable findings. Furthermore, although Sanders et al. state that baseline prevalence of risk factors for falls and fractures was similar in both the supplemented and placebo groups, the physical activity profile of the two experimental groups is not reported. This is a confounding factor given that physical activity is a valuable counter measure for sarcopenia (Forbes et al. 2012), thus disparity in the physical activity profile of the two experimental groups is of importance when interpreting this data.
We also report that measurement of iPTH displayed an inverse relationship with serum $25[\mathrm{OH}] \mathrm{D}$, in line with previous data (Sai et al. 2011). PLB showed elevated iPTH concentration whereas the opposite was observed for VITD, which may be explained by the understanding that 1,25-dihydroxyvitamin $\mathrm{D}$ represses the transcription of the PTH gene and also indirectly regulates PTH secretion by regulating the expression of calcium sensing receptors (Kumar and Thompson 2011). Thus, in addition to providing evidence that our findings produce no negative effect of high serum 25[OH]D concentrations $\left(>100 \mathrm{nmol} \mathrm{L}^{-1}\right)$ on skeletal muscle function, we further demonstrate that our supplementation protocol offers a positive effect on the maintenance of iPTH concentrations. It is reported that high serum 25[OH]D concentrations $\left(>100 \mathrm{nmol} \mathrm{L}^{-1}\right)$ may be necessary for disease prevention (Heaney 2011; Vieth 2011), thus we demonstrate that such concentrations needed to optimise other biological functions are unlikely to be detrimental to the normal function of skeletal muscle.

It is important to also consider the available evidence that suggests vitamin D supplementation has a beneficial impact on muscle function. Case studies have previously described a proximal muscle weakness associated with nutritional osteomalacia that is responsive to supplementation with vitamin D (Ziambaras and Dagogo-Jack 1997; Irani 1976; Smith and Stern 1967; Al-Said et al. 2009). Recently, in contrast to our current findings, we have observed an improvement in 10-m sprint times and vertical jump height following supplementation in a group of vitamin D deficient young athletes (Close et al. 2013b). A recent trial has also demonstrated in a sample of severely deficient individuals (all $<15 \mathrm{nmol} \mathrm{L}^{-1}$ ) that supplementation with 20,000 IU of vitamin $\mathrm{D}_{3}$ on alternate days for 10-12 weeks significantly elevated serum $25[\mathrm{OH}]$ $\mathrm{D}\left(>100 \mathrm{nmol} \mathrm{L}{ }^{-1}\right)$ and resulted in significant improvements in phosphocreatine recovery half-time $\left(\tau^{1 / 2} \mathrm{PCr}\right)$ of the soleus muscle, indicative of improved mitochondrial oxidative function as measured by ${ }^{31} \mathrm{P}$-magnetic resonance spectroscopy (Sinha et al. 2013). Furthermore, in a systematic review previously mentioned (Stockton et al. 2011), the authors also discuss that though participants with baseline $25[\mathrm{OH}] \mathrm{D}>25 \mathrm{nmol} \mathrm{L}^{-1}$ show no change in muscle strength with vitamin D supplementation, a limited number of trials demonstrate an increase in proximal muscle strength in adults with vitamin D deficiency. A common underlying feature of these positive outcome trials is that a large portion of the sample population exhibited severe vitamin $\mathrm{D}$ deficiency $\left(<12 \mathrm{nmol} \mathrm{L}^{-1}\right)$ at baseline that was corrected with vitamin $\mathrm{D}_{3}$ supplementation. It is reasonable to postulate based on such findings that skeletal muscle function only displays perceptible perturbations in function when vitamin D status of the sample population reaches concentrations $<12 \mathrm{nmol} \mathrm{L}^{-1}$. 
Taking the available evidence into account, we propose a possible reason that an improvement in muscle function was not detected in the current study, because muscle function was not impaired to begin with as no participants had serum $25[\mathrm{OH}] \mathrm{D}$ concentrations in the range $<12 \mathrm{nmol} \mathrm{L}^{-1}$. If one assumes a sigmoidal physiological response of skeletal muscle to vitamin $\mathrm{D}$, it may be difficult to detect a response when nutrient status is already on the ascending limb or plateau of the response curve (Lappe and Heaney 2012). Thus skeletal muscle may only display sharp decrements in function at serum $25[\mathrm{OH}] \mathrm{D}$ concentrations $<12 \mathrm{nmol} \mathrm{L}^{-1}$, but thereafter shows no perceptible added benefit of the increasing concentrations. This could be due to a disturbance of systemic and intracellular calcium concentrations that occur in severe deficiency, affecting both contractile activity and intracellular signalling, and a notion previously put forward (Girgis et al. 2012). Although speculative, this would explain much of the human data available on vitamin D status and muscle function.

We acknowledge that there were limitations in the current study design regarding supplemental dose and response. We did not measure markers of vitamin D toxicity thus compromising the efficacy of our supplementation protocol. An early indication of adverse effects to vitamin D supplementation is hypercalciuria (Vieth 2007); however, this was not monitored in the current trial. Symptoms of vitamin D toxicity are wholly attributable to hypercalcemia/hypercalciuria, including nausea, dehydration and lethargy. No participants reported any of the associated symptoms. The dose of $10,000 \mathrm{IU}$ day $^{-1}$ was selected as previous trials including our own (Close et al. 2013a) have failed to achieve the desired serum 25[OH]D concentrations $>100 \mathrm{nmol} \mathrm{L}^{-1}$ with lower doses. In addition, data have demonstrated that oral vitamin $\mathrm{D}$ intakes of 9,600 IU day ${ }^{-1}$ are needed to obtain serum 25[OH] D concentrations above $100 \mathrm{nmol} \mathrm{L}{ }^{-1}$ in $97 \%$ of a large cohort of 3,667 participants (Garland et al. 2011). Clinical trial evidence and dermal photosynthesis of vitamin $\mathrm{D}$ following UVB exposure supports our assumption that a prolonged daily dose of $10,000 \mathrm{IU} \cdot \mathrm{day}^{-1}$ is unlikely to cause adverse effects in otherwise healthy persons (Vieth 2007). The authors are, however, in support of toxicity monitoring in future trials that employ high daily doses of vitamin D. Further, our sample size calculation determined that to enable a $10 \%(21 \mathrm{Nm})$ increase in peak torque between pre-supplementation and post-supplementation with $80 \%$ power, $n=24$ was required. Although 29 participants completed supplementation and blood sampling, only 22 completed all muscle function trials. This is a potential confounding factor, however, it may be argued given that no trends were observed, and $P$-values were strongly nonsignificant that it is unlikely a two-participant deficit that significantly affected our findings.

\section{Conclusions}

In summary, the current investigation has added to a body of evidence that suggests young healthy adults present with inadequate and deficient vitamin $\mathrm{D}$ concentrations in the winter months. We have demonstrated that elevating serum $25[\mathrm{OH}] \mathrm{D}$ concentrations in a predominantly insufficient group to concentrations $>100 \mathrm{nmol} \mathrm{L}^{-1}$ may be effectively achieved by daily supplementation with $10,000 \mathrm{IU}$ vitamin $\mathrm{D}_{3}$ (cholecalciferol); however, this does not improve or negate skeletal muscle function. We propose that muscle function of healthy young adults is likely only aberrant in a state of severe vitamin D deficiency $\left(<12 \mathrm{nmol} \mathrm{L}^{-1}\right)$ and thus future work should assess this. Due to the inter-individual variation in baseline vitamin $\mathrm{D}$ status and response to supplementation, it is crucial that the baseline vitamin D concentration of the sample population being tested is considered in any interventional trial as this may have a significant impact upon the outcome of the trial.

Acknowledgments The authors would like to thank Dr. Rob Erskine and Ian Poole at LJMU for their expert technical assistance in electromyostimulation. Gratitude is also expressed by the authors to Emily Fisher, Christopher Washbourne and Isabelle Piec at UEA for the development of the LC-MS/MS assay.

Conflict of interest The authors declare no conflicts of interest.

\section{References}

Al-Said YA, Al-Rached HS, Al-Qahtani HA, Jan MM (2009) Severe proximal myopathy with remarkable recovery after vitamin D treatment. Can J Neurol Sci Le journal canadien des sciences neurologiques 36(3):336-339

Anderson PH, Turner AG, Morris HA (2012) Vitamin D actions to regulate calcium and skeletal homeostasis. Clin Biochem 45(12):880-886. doi:10.1016/j.clinbiochem.2012.02.020

Atkinson G, Nevill AM (1998) Statistical methods for assessing measurement error (reliability) in variables relevant to sports medicine. Sports Med 26(4):217-238

Baltzopoulos V, Brodie DA (1989) Isokinetic dynamometry. Applications and limitations. Sports Med 8(2):101-116

Bigland-Ritchie B, Jones DA, Woods JJ (1979) Excitation frequency and muscle fatigue: electrical responses during human voluntary and stimulated contractions. Exp Neurol 64(2):414-427

Bischoff-Ferrari HA, Dietrich T, Orav EJ, Hu FB, Zhang Y, Karlson EW, Dawson-Hughes B (2004) Higher 25-hydroxyvitamin D concentrations are associated with better lower-extremity function in both active and inactive persons aged $>$ or $=60 \mathrm{y}$. Am J Clin Nutr 80(3):752-758

Capiati DA, Vazquez G, Tellez Inon MT, Boland RL (2000) Role of protein kinase $\mathrm{C}$ in $1,25(\mathrm{OH})(2)$-vitamin $\mathrm{D}(3)$ modulation of intracellular calcium during development of skeletal muscle cells in culture. J Cell Biochem 77(2):200-212

Close GL, Leckey J, Patterson M, Bradley W, Owens DJ, Fraser WD, Morton JP (2013a) The effects of vitamin D3 supplementation on serum total $25[\mathrm{OH}] \mathrm{D}$ concentration and physical performance: a randomised dose-response study. Br J Sports Med 47(11):692696. doi:10.1136/bjsports-2012-091735 
Close GL, Russell J, Cobley JN, Owens DJ, Wilson G, Gregson W, Fraser WD, Morton JP (2013b) Assessment of vitamin D concentration in non-supplemented professional athletes and healthy adults during the winter months in the UK: implications for skeletal muscle function. J Sports Sci 31(4):344-353. doi:10.1080/02 640414.2012.733822

de Boland AR, Massheimer V, Fernandez LM (1988) 1,25 Dihydroxyvitamin D3 affects calmodulin distribution among subcellular fractions of skeletal muscle. Calcif Tissue Int 43(6):370-375

Drouin JM, Valovich-mcLeod TC, Shultz SJ, Gansneder BM, Perrin DH (2004) Reliability and validity of the Biodex system 3 pro isokinetic dynamometer velocity, torque and position measurements. Eur J Appl Physiol 91(1):22-29. doi:10.1007/ s00421-003-0933-0

Food and Drug Administration, U.S. Department of Health and Human Services. (2001) Guidance for Industry: Bioanalytical Method Validation. Retrieved on December 17th 2013 from http://www.fda.gov/downloads/Drugs/Guidances/ucm070107.pdf

Forbes SC, Little JP, Candow DG (2012) Exercise and nutritional interventions for improving aging muscle health. Endocrine 42(1):29-38. doi:10.1007/s12020-012-9676-1

Garcia LA, Ferrini MG, Norris KC, Artaza JN (2013) 1,25(OH)(2) vitamin $\mathrm{D}(3)$ enhances myogenic differentiation by modulating the expression of key angiogenic growth factors and angiogenic inhibitors in $\mathrm{C}(2) \mathrm{C}(12)$ skeletal muscle cells. J Steroid Biochem Mol Biol 133:1-11. doi:10.1016/j.jsbmb.2012.09.004

Garland CF, French CB, Baggerly LL, Heaney RP (2011) Vitamin D supplement doses and serum 25-hydroxyvitamin $\mathrm{D}$ in the range associated with cancer prevention. Anticancer Res 31(2):607-611

Gerdhem P, Ringsberg KA, Obrant KJ, Akesson K (2005) Association between 25-hydroxy vitamin D levels, physical activity, muscle strength and fractures in the prospective population-based OPRA Study of Elderly Women. Osteoporos Int 16(11):1425-1431. doi:10.1007/s00198-005-1860-1

Gerrits HL, Hopman MT, Sargeant AJ, Jones DA, De Haan A (2002) Effects of training on contractile properties of paralyzed quadriceps muscle. Muscle Nerve 25(4):559-567

Girgis CM, Clifton-Bligh RJ, Hamrick MW, Holick MF, Gunton JE (2012) The roles of vitamin D in skeletal muscle: form, function, and metabolism. Endocr Rev. doi:10.1210/er.2012-1012

Heaney RP (2011) Assessing vitamin D status. Curr Opin Clin Nutr Metab Care 14(5):440-444. doi:10.1097/MCO.0b013e328348ed85

Heaney RP, Davies KM, Chen TC, Holick MF, Barger-Lux MJ (2003) Human serum 25-hydroxycholecalciferol response to extended oral dosing with cholecalciferol. Am J Clin Nutr 77(1):204-210

Hermsen D, Franzson L, Hoffmann JP, Isaksson A, Kaufman JM, Leary E, Muller C, Nakatsuka K, Nishizawa Y, Reinauer H, Riesen W, Roth HJ, Steinmuller T, Troch T, Bergmann P (2002) Multicenter evaluation of a new immunoassay for intact PTH measurement on the Elecsys System 2010 and 1010. Clin Lab 48(3-4):131-141

Hossein-nezhad A, Spira A, Holick MF (2013) Influence of vitamin D status and vitamin D3 supplementation on genome wide expression of white blood cells: a randomized double-blind clinical trial. PLoS ONE 8(3):e58725. doi:10.1371/journal.pone.0058725

Houston DK, Cesari M, Ferrucci L, Cherubini A, Maggio D, Bartali B, Johnson MA, Schwartz GG, Kritchevsky SB (2007) Association between vitamin $\mathrm{D}$ status and physical performance: the InCHIANTI study. J Gerontol Ser A Biol Sci Med Sci 62(4):440-446

IoM (2011) Dietary reference intakes for calcium and vitamin D. National Academic Press, Washington, DC

Irani PF (1976) Electromyography in nutritional osteomalacic myopathy. J Neurol Neurosurg Psychiatry 39(7):686-693

Kenny AM, Biskup B, Robbins B, Marcella G, Burleson JA (2003) Effects of vitamin D supplementation on strength, physical function, and health perception in older, community-dwelling men. J Am Geriatr Soc 51(12):1762-1767

Kukuljan S, Nowson CA, Sanders KM, Nicholson GC, Seibel MJ, Salmon J, Daly RM (2011) Independent and combined effects of calcium-vitamin D3 and exercise on bone structure and strength in older men: an 18-month factorial design randomized controlled trial. J Clin Endocrinol Metab 96(4):955-963. doi:10.12 10/jc.2010-2284

Kumar R, Thompson JR (2011) The regulation of parathyroid hormone secretion and synthesis. J Am Soc Nephrol JASN 22(2):216-224. doi:10.1681/ASN.2010020186

Lappe JM, Heaney RP (2012) Why randomized controlled trials of calcium and vitamin D sometimes fail. Dermatoendocrinol 4(2):95-100. doi:10.4161/derm.19833

Lesmes GR, Costill DL, Coyle EF, Fink WJ (1978) Muscle strength and power changes during maximal isokinetic training. Med Sci Sports 10(4):266-269

Marantes I, Achenbach SJ, Atkinson EJ, Khosla S, Melton LJ 3rd, Amin S (2011) Is vitamin D a determinant of muscle mass and strength? J Bone Miner Res 26(12):2860-2871. doi: $10.1002 / j b m r .510$

Morelli S, de Boland AR, Boland RL (1993) Generation of inositol phosphates, diacylglycerol and calcium fluxes in myoblasts treated with 1,25-dihydroxyvitamin D3. Biochem J 289(Pt 3):675-679

Morton JP, Atkinson G, MacLaren DP, Cable NT, Gilbert G, Broome C, McArdle A, Drust B (2005) Reliability of maximal muscle force and voluntary activation as markers of exerciseinduced muscle damage. Eur J Appl Physiol 94(5-6):541-548. doi:10.1007/s00421-005-1373-9

Morton JP, Iqbal Z, Drust B, Burgess D, Close GL, Brukner PD (2012) Seasonal variation in vitamin D status in professional soccer players of the English Premier League. Appl Physiol Nutr Metab. doi:10.1139/h2012-037

Rodman JS, Baker T (1978) Changes in the kinetics of muscle contraction in vitamin D-depleted rats. Kidney Int 13(3):189-193

Rosen CJ, Adams JS, Bikle DD, Black DM, Demay MB, Manson JE, Murad MH, Kovacs CS (2012) The nonskeletal effects of vitamin D: an Endocrine Society scientific statement. Endocr Rev 33(3):456-492. doi:10.1210/er.2012-1000

Sai AJ, Walters RW, Fang X, Gallagher JC (2011) Relationship between vitamin $\mathrm{D}$, parathyroid hormone, and bone health. J Clin Endocrinol Metab 96(3):E436-E446. doi:10.1210/jc.2010-1886

Sanders KM, Stuart AL, Williamson EJ, Simpson JA, Kotowicz MA, Young D, Nicholson GC (2010) Annual high-dose oral vitamin D and falls and fractures in older women: a randomized controlled trial. JAMA 303(18):1815-1822. doi:10.1001/jama.2010.594

Sinha A, Hollingsworth KG, Ball S, Cheetham T (2013) Improving the vitamin $d$ status of vitamin d deficient adults is associated with improved mitochondrial oxidative function in skeletal muscle. J Clin Endocrinol Metab 98(3):E509-E513. doi:10.121 0/jc.2012-3592

Smith R, Stern G (1967) Myopathy, osteomalacia and hyperparathyroidism. Brain 90(3):593-602

Snellman G, Melhus H, Gedeborg R, Byberg L, Berglund L, Wernroth L, Michaelsson K (2010) Determining vitamin D status: a comparison between commercially available assays. PLoS ONE 5(7):e11555. doi:10.1371/journal.pone.0011555

Soderlund K, Hultman E (1991) ATP and phosphocreatine changes in single human muscle fibers after intense electrical stimulation. Am J Physiol 261(6 Pt 1):E737-E741

Srikuea R, Zhang X, Park-Sarge OK, Esser KA (2012) VDR and CYP27B1 are expressed in $\mathrm{C} 2 \mathrm{C} 12$ cells and regenerating skeletal muscle: potential role in suppression of myoblast proliferation. Am J Physiol Cell Physiol 303(4):C396-C405. doi:10.1152/ajp cell.00014.2012 
Stockton KA, Mengersen K, Paratz JD, Kandiah D, Bennell KL (2011) Effect of vitamin D supplementation on muscle strength: a systematic review and meta-analysis. Osteoporos Int 22(3):859871. doi:10.1007/s00198-010-1407-y

Stratos I, Li Z, Herlyn P, Rotter R, Behrendt AK, Mittlmeier T, Vollmar B (2013) Vitamin D increases cellular turnover and functionally restores the skeletal muscle after crush injury in rats. Am J Pathol 182(3):895-904. doi:10.1016/j.ajpath.2012.11.006

van Schoor NM, Lips P (2011) Worldwide vitamin D status. Best Pract Res Clin Endocrinol Metab 25(4):671-680. doi:10.1016/j.beem.2011.06.007

Vazquez G, Boland R, de Boland AR (1995) Modulation by 1,25(OH)2-vitamin D3 of the adenylyl cyclase/cyclic AMP pathway in rat and chick myoblasts. Biochim Biophys Acta 1269(1):91-97

Vieth R (2007) Vitamin D toxicity, policy, and science. J Bone Miner Res 22(Suppl 2):V64-V68. doi:10.1359/jbmr.07s221

Vieth R (2011) Why the minimum desirable serum 25-hydroxyvitamin D level should be $75 \mathrm{nmol} / \mathrm{L} \quad(30 \mathrm{ng} / \mathrm{ml})$. Best Pract Res Clin Endocrinol Metab 25(4):681-691. doi:10.1016/j.beem.2011.06.009

Ziambaras K, Dagogo-Jack S (1997) Reversible muscle weakness in patients with vitamin D deficiency. West J Med 167(6):435-439

Zittermann A (2003) Vitamin D in preventive medicine: are we ignoring the evidence? Br J Nutr 89(5):552-572. doi:10.1079/ BJN2003837 